Learning to become a primary care professional: insights from threshold concept theory.

\author{
Neve, Hilary
}

http://hdl.handle.net/10026.1/12904

10.1080/14739879.2018.1533390

Education for Primary Care

Taylor \& Francis

All content in PEARL is protected by copyright law. Author manuscripts are made available in accordance with publisher policies. Please cite only the published version using the details provided on the item record or document. In the absence of an open licence (e.g. Creative Commons), permissions for further reuse of content should be sought from the publisher or author. 
Learning to become a Primary Care Professional: Insights from

\section{Threshold Concept Theory}

Hilary Neve

Peninsula Medical School, Faculty of Medicine and Dentistry, University of Plymouth,

Plymouth, UK

Correspondence details

C413 Portland Square, Drake Circus, Plymouth, PL4 8AA, UK

Tel: 01752586802

hilary.neve@plymouth.ac.uk 


\title{
Learning to become a Primary Care Professional: Insights from
}

\section{Threshold Concept Theory}

\begin{abstract}
Threshold Concepts are fundamental ideas within a discipline which are transformative, integrative, irreversible and often troublesome. This article describes the threshold concept framework and discusses how it can offer new insights into how we focus teaching and facilitate learning around these concepts, such as uncertainty. Relevant research from a range of health disciplines are explored to consider which concepts may be critical to thinking and practising effectively in primary care. In addition, it is proposed that threshold concepts may have relevance to the GP recruitment crisis.
\end{abstract}

Keywords: primary care, general practice, threshold concepts, education

\section{Introduction}

Maria, your GP trainee, has been with your practice for a few weeks. You thought she was settling in well but today, at your regular supervision session, she seems upset. She tells you about the patients she has seen that morning who all had complex problems or unsorted chronic conditions. She describes how she "couldn't work out what was wrong with anyone" and that she cannot imagine how she will ever know enough to be a GP. She particularly misses the rapid and reassuring access to investigations that she had in the hospital.

You explain that many trainees struggle to deal with uncertainty when they leave the hospital setting. You recommend an article on 'managing ambiguity' for 
Maria to read and suggest that she sits in with other GPs to observe how they deal with uncertainty. You meet regularly to reflect on her learning and, as the months pass, you see her confidence and skills at dealing with undifferentiated cases improve. She describes realising that many problems have no single right answer and that it's OK not to know everything. She discovers that asking patients "what do you think is going on?" can be very helpful and that many problems are multifactorial and become clearer over time. When you hear her enthusiastically explaining to a medical student that "uncertainty is what makes general practice interesting", you realise she has finally pulled these ideas together, crossed a threshold in learning and understood uncertainty.

You discuss Maria's story at a trainers' conference and somebody mentions the Threshold Concept Framework. You do some reading and the ideas resonate with you. You are intrigued to discover that 'uncertainty' has been identified as a Threshold Concept (TC) in research studies with nursing and medical students [1,2], palliative care registrars [3] and trainees in internal medicine [4]. You wonder about other TCs in primary care and whether the framework can throw further light on your teaching. You decide to find out more.

\section{What are Threshold Concepts?}

The Threshold Concept Framework (TCF) is an educational theory, developed by Meyer and Land in 2003 [5], following an extensive study within higher education. They discovered that there were certain core ideas which, once grasped, opened up a whole new perspective for the learner, radically transforming their understanding of a subject, They called these ideas Threshold Concepts and suggested that, while they are difficult to learn, understanding them is essential to the mastery of any field. Hundreds of papers drawing on the TCF have since been published across multiple disciplines 
including the health professions and, more recently, in medical education.

Threshold Concepts (TCs) are much more than key concepts, the building blocks of knowledge. Importantly, TCs are transformative. This not only leads to a change in how the learner sees a subject but often involves a shift in their own identify and how they see themselves or view the world. In the example above, Maria came to view uncertainty, her own role in dealing with uncertainty and the role of a GP differently. As learners grapple with a TC they are said to pass through a liminal space where learning is usually troublesome and where they may oscillate in their understanding. It may, as in Maria's case, take considerable time before the learner progresses through the liminal space, reaches and crosses the threshold to mastery. 'Getting' a threshold concept is often associated with an 'aha' moment which may be less about gaining new knowledge, but more about integration - the coming together of different strands of knowledge that the learner had not previously realised were connected. Once fully grasped, the threshold concept is said to be irreversible and difficult to unlearn [5].

\section{Threshold concepts and primary care}

While there is limited research exploring TCs in primary care, concepts identified in other medical and healthcare settings may be relevant. TCs identified in the literature include 'the complexity of care' [6,7], the 'holistic approach' [8], 'consider the whole person' [2], 'caring' [9] and 'collective competence' (the recognition that effective care requires collaboration with other team members) [4]. Patient, or client-centredness has been identified as a threshold concept for pharmacists [10], medical trainees in hospital [4] and occupational therapists [8]. Work with nurses highlights an essential part of patient-centredness - the TC of overcoming bias and stigma [7]. Crossing thresholds 
may transform the way learners think and approach practice, such that they themselves become different. For example, Evidence Based Practice (EBP) $[8,11]$ and the biopsychosocial model [Roshni Khatri, personal communication] have both been identified as likely threshold concepts in healthcare. Once nurses understand the concept of EBP, they become the kind of practitioner who thinks about evidence when faced with clinical problems [11]. Likewise, the shift from a medical to social model of health can powerfully transform how healthcare professions see and deal with situations [12].

\section{Disciplinary aspects of TCs}

Learning to become a primary care professional involves understanding 'ways of thinking and practising', the underpinning values and ways of being that are key to becoming part of a disciplinary community [13]. While some threshold concepts, such as reflective practice $[8,14]$, may be generic across disciplines, others may be discipline specific or have a particular focus or meaning depending on the health professional's context.

As trainees move from secondary to primary care, their roles change and they often have to shift or expand their understanding. As Maria discovered, the move to general practice, where patients often have complex undifferentiated conditions, is often associated with "a sharp surge in uncertainty" [15 p61]. Patient-centredness is an important element of care in any setting and a study of hospital trainees found that grasping the importance of 'exploring a patient's perspectives and goals' [4] was transformative. GP trainees, however, discover that in primary care the concept 'patientcentredness' has new meanings - in particular it involves the building and maintenance of relationships over time [15]. Similarly hospital trainees often struggle with the TC 
'burden of responsibility': their duty to ensure patients receive good care [4]. The huge sense of responsibility felt by GP trainees, however, relates more to their move to the frontline of care [15] where they have limited access to diagnostic testing [16]. The shift from hospital to primary care also brings with it a responsibility to address population, as well as individual patients' needs. This is likely to require the crossing of additional thresholds, such as understanding health inequalities [17], social justice [18], 'understanding the bigger picture' [2] and the importance of caring for people who are socially or culturally marginalised [7], all of which have been identified as TCs in healthcare education.

\section{What this means for primary care education}

Research has often focused on identifying which concepts are threshold within a particular discipline. Arguably more important is how the TCF can help us look differently at teaching and learning and positively influence our practice as educators [19]. The following suggests ways we can use the framework to promote meaningful learning experiences and support learners as they develop as primary care professionals.

\section{Threshold concepts as a focus}

Primary care educators may feel overwhelmed by the responsibility to prepare learners to deal with 'anything and everything' that comes through the door. Threshold concepts can be useful here, by helping us to consider and focus our attention on those concepts which are fundamental to understanding primary care. Indeed it has even be suggested that we should reconceptualise our curricula "from 'content to be covered' to "thresholds to be crossed"' [20 p.213]. Ensuring health professionals cross these fundamental thresholds may be vital for effective patient care. For example, doctors 
who struggle to manage uncertainty tend to refer and investigate patients more, as well as experiencing more work-related stress [21].

\section{Addressing troublesome knowledge}

When learners are struggling with areas of their work, this may not necessarily reflect the quality of our teaching, or problems with the learning environment, but may be because some concepts are particularly troublesome to master. Appreciating this, and that learners may respond by resisting, disengaging or even giving negative course feedback, can be transformative for educators. Learning may be troublesome for a range of reasons: for example the concept may be complex, counterintuitive, emotionally difficult or 'inert' (the learner cannot connect it to anything they already know) [22]. Where crossing a threshold requires learners to let go of previous beliefs or ways of seeing the world, this can be particularly difficult.

As educators, we need to notice how learners respond when stuck [2] and look out for evidence of superficial understandings or mimicry (for example, learners using new disciplinary language which they cannot fully explain) so that we can help them progress through the liminal space. Understanding why a concept is troublesome can help us find appropriate ways to support them. Learning to identify and manage uncertainty, for example, requires a complex set of skills and understandings. It also requires learners to let go of the idea that there are absolute answers in medicine [2] and this can be anxiety-provoking and frightening. For Maria, moving forward involved reflection, support and recursiveness (revisiting concepts in new ways, over time) [23]. Introducing learners themselves to TCs and the notion that important learning often involves struggle and takes time, may also be useful. This may have been reassuring for Maria. 
Sometimes we ourselves as educators are the bottleneck. The irreversible nature of TCs means that a difficult concept may now seem obvious to us and we may not remember that we once found it troublesome to understand - or why. Supporting learners to make their thinking visible alone or in small groups (for example using visual diagrams or concept maps) [24] can often help identify and address the missing step in their understanding.

\section{Connecting threshold concepts}

Threshold Concepts are increasingly being recognised as interconnected rather than as independent elements of knowledge. This suggests that helping learners to see connections between TCs and linking TCs to clinical experiences, may be as important as understanding the individual concepts themselves [22]. This may be particularly important when working with patients who have multiple morbidities or whose needs are complex and inter-related [6]. Crossing one threshold may help the learner cross others. For example, as Maria's story illustrates, understanding related TCs such as 'I don't have to know everything' [2], the positive benefits of 'active inaction' [3], that resolution can be open-ended [15], how listening and 'being there' for the patient can be important than solving problems $[3,15]$ and that expertise involves much more than allknowingness [16] may all increase learners' ability to manage uncertainty.

\section{Conclusion and final thoughts}

The TCF offers us a new way of identifying and exploring those concepts which may be fundamental to thinking and practising effectively in primary care. It reminds us that becoming a primary care professional takes time, involves struggle and significant transformative shifts. The TCF can also help us understand when and how to support, 
guide or challenge learners. Exploring with learners the threshold concepts reviewed in this article, making them visible through discussion of significant experiences in practice $[2,15]$ and building in opportunities to revisit and deepen understandings, is likely to be a very valuable use of time. Indeed, helping learners to cross troublesome but vital thresholds so that they are able to accept and embrace uncertainty [3], understand and work with the biopsychosocial model and grasp the importance to practice of inequalities in health and the inverse care law, may be some of the most important roles of a primary care educator.

There are also thresholds to cross in our development as educators and at times we may all struggle and feel stuck in the liminal space. Concepts such as 'active learning' and even 'threshold concepts' themselves may be thresholds for educators. Perhaps more importantly, conversations with other educators about TCs can offer a new lens for us to reflect, and gain different insights into, how we plan teaching and facilitate learning.

A final thought relates to the current crisis in recruiting professionals, particularly GPs, to primary care. Explanations often focus on issues such as the role of the media, the hidden curriculum, tribalism and negative public perceptions of the GP role $[25,26]$. While educators have limited influence over some of these issues [26] threshold concepts offer another perspective. If learners remain in the liminal space and fail to cross the thresholds required to understand, think and practise like a GP, are they likely to choose to work in general practice? If this is a significant barrier, then a focus on threshold concepts within educational programmes could be could be a new approach to addressing the recruitment problem. 


\section{References}

[1] Corbally M, Kirwan A, O’Neill C, Kelly M. Simulating Troublesome Contexts: How Multiple Roles within Ward-Based Simulations Promote Professional Nursing Competence. International Journal of Practice-based Learning in Health and Social Care. 2018;6(1):18-23.

[2] Neve H, Lloyd H, Collett T. Understanding students' experiences of professionalism learning: a ‘threshold' approach. Teach High Educ. 2017;22(1):92-108.

[3] Wearn A, O’Callaghan A, Barrow M. Becoming a Different Doctor: Identifying Threshold Concepts: When Doctors in Training Spend Six Months with a Hospital Palliative Care Team. In: Land R, Meyer JHF, Flanagan MT, editors. Threshold concepts in practice. Rotterdam Boston Taipei: Sense Publishers; 2016. p. 223-38.

[4] Bhat C, Burm S, Mohan T, Chahine S, Goldszmidt M. What trainees grapple with: a study of threshold concepts on the medicine ward. Medical education. 2018;52(6):62031.

[5] Meyer JHF, Land R. Threshold Concepts and Troublesome Knowledge (1) Linkages to Ways of Thinking and Practising. In: Rust C, editor. Improving Student Learning - Ten Years On. Oxford:OCSLD; 2003. p. 412-24.

[6] Wilkinson I. Nurturing and Complexity-Threshold Concepts in Geriatric Medicine. International Journal of Practice-based Learning in Health and Social Care. 2018; 6(1):64-77.

[7] McAllister M, Lasater K, Stone TE, Levett-Jones T. The reading room: exploring the use of literature as a strategy for integrating threshold concepts into nursing curricula. Nurse education in practice. 2015;15(6):549-55.

[8] Nicola-Richmond KM, Pépin G, Larkin H. Transformation from student to occupational therapist: Using the Delphi technique to identify the threshold concepts of occupational therapy. Australian occupational therapy journal. 2016;63(2):95-104.

[9] Clouder L. Caring as a 'threshold concept': transforming students in higher education into health(care) professionals. Teach High Educ. 2005;10(4):505-17. 
[10] Kolar C. Across the Patient Care Practitioner Threshold: Identifying Threshold Concepts and Evaluating the Teaching of the Pharmacists' Patient Care Process. [dissertation]. University of Minnesota; 2017.

[11] Martindale L. Threshold concepts in research and evidence-based practice: Investigating troublesome learning for undergraduate nursing students [dissertation]. Durham University: 2017.

[12] Land R, Neve H, Martindale L. Threshold Concepts, Action Poetry and the Health Professions: An Interview with Ray Land. International Journal of Practice-based Learning in Health and Social Care. 2018;6(1):45-52.

[13] MCcune V, Hounsell D. The development of students' ways of thinking and practising in three final-year biology courses. High Educ. 2005;49(3):255-89.

[14] Corrall S. Crossing the threshold: reflective practice in information literacy development. J Inf Lit. 2017;11(1):23.

[15] Vaughan K, Bonne L, Eyre J. Knowing Practice: Vocational Thresholds for GPs, Carpenters, Engineering Technicians: Summary Report. New Zealand Council for Educational Research; 2015.

[16] Vaughan K. Vocational thresholds: developing expertise without certainty in general practice medicine. Journal of primary health care. 2016;8(2):99-105.

[17] Chittleborough C. Threshold concepts in a flipped classroom to facilitate learning about health inequalities. HERGA Conference 2013 Sept 25-27; Adelaide, Australia. Available from:

http://www.herga.com.au/uploads/2/2/1/2/22122258/herga_conference book_sept 201 $\underline{3 . p d f}$

[18] Levett-Jones T, Bowen L, Morris A. Enhancing nursing students' understanding of threshold concepts through the use of digital stories and a virtual community called 'Wiimali'. Nurse education in practice. 2015;15(2):91-6. 
[19] Barradell S, Kennedy-Jones M. Threshold concepts, student learning and curriculum: making connections between theory and practice. Innovations in Education and Teaching International. 2015;52(5):536-45.

[20] Kinchin IM, Cabot LB, Kobus M, Woolford M. Threshold concepts in dental education. European Journal of Dental Education. 2011;15(4):210-5.

[21] Taylor D, Picker B, Woolever D, Thayer E, Carney P, Galper A. A Pilot Study to Address Tolerance of Uncertainty Among Family Medicine Residents. Family medicine. 2018;50(7):531-8.

[22] Perkins D. Constructivism and Troublesome Knowledge. In: Meyer J, Land R, editors. Overcoming barriers to student understanding: threshold concepts and troublesome knowledge. London; New York: Routledge; 2006. p. 33-47.

[23] Cousin G. An introduction to threshold concepts. Planet. 2006 Dec;17(1):4-5.

[24] Neve H, Gilbert K, Lloyd H. PBL as Learning vehicle, Threshold Concept or Capability? Audio-diary research in medical education. In: Savin-Baden M, Tombs G, editors. Threshold Concepts and Problem-based Learning. Sense Publishers; 2018.

[25] Wass V, Gregory S, Petty-Saphon K. By choice — not by chance: supporting medical students towards future careers in general practice. London: Health Education England and the Medical Schools Council. 2016.

[26] Jones R. GP recruitment and medical education: part of the solution? Education for Primary Care. 2017;28(6):304-6. 